\title{
Efektivitas Model Pembelajaran Kooperatif Tipe Pair Checks Ditinjau dari Kecerdasan Interpersonal terhadap Kompetensi Pengetahuan Matematika
}

\author{
*G.N. Sastra Agustika1 , A.A. Wahyu Kartika², I. Wyn Wiarta ${ }^{3}$ \\ ${ }^{123}$ Jurusan Pendidikan Guru Sekolah Dasar, Fakultas I lmu Pendidikan, Universitas Pendidikan Ganesha, Indonesia
}

\author{
A R T I C L E I N F O \\ Article history: \\ Received 10 May 2019 \\ Received in revised form \\ 10 June 2019 \\ Accepted 15 July 2019 \\ Available online 29 August \\ 2019 \\ Kata Kunci: \\ pair checks, kecerdasan \\ interpersonal, matematika \\ Keywords: \\ pair checks, interpersonal \\ intelligence, mathematics
}

\begin{abstract}
A B S T R A K
Penelitian ini bertujuan untuk mengetahui efektivitas model pembelajaran kooperatif tipe pair checks ditinjau dari kecerdasan interpersonal terhadap kompetensi pengetahuan Matematika kelas IV SDN Gugus Moh. Hatta tahun ajaran 2018/2019. Penelitian ini merupakan eksperimen semu dengan rancangan factorial Design $2 \times 2$. Populasi penelitian ini adalah kelas IV SDN Gugus Moh. Hatta tahun ajaran 2018/2019, dengan banyak siswa 244 orang. Teknik Sampel yang digunakan pada penelitian ini adalah purposive sampling. Data dikumpulkan menggunakan metode tes dan non-tes. Data dianalisis menggunakan analisis variansi dua jalur. Berdasarkan hasil analisis, diperoleh (1) terdapat perbedaan yang signifikan kompetensi pengetahuan Matematika antara kelompok siswa yang dibelajarkan melalui model pembelajaran kooperatif tipe pair checks dan kelompok siswa yang dibelajarkan menggunakan pembelajaran konvensional, (2)
\end{abstract}

tidak terdapat perbedaan yang signifikan kompetensi pengetahuan Matematika antara siswa yang memiliki kecerdasan interpersonal tinggi dan siswa yang memiliki kecerdasan interpersonal rendah, (3) tidak terdapat interaksi yang signifikan antara model pembelajaran kooperatif tipe pair checks dan kecerdasan interpersonal terhadap kompetensi pengetahuan Matematika. Hasil perhitungan efektivitas perlakuan diperoleh nilai $\eta^{2}=0,052$ sehingga dapat disimpulkan bahwa penerapan model pembelajaran memiliki pengaruh terhadap kompetensi pengetahuan Matematika sebesar $5,2 \%$.

\section{A B S T R A C T}

This study aimed to find out the effectiveness of Pair Checks cooperative learning model type observed from interpersonal intelligence toward Mathematical competency on the fourth grade at SDN Moh. Hatta in 2018/2019 academic year. This study was a quasi-experimental design with $2 \times 2$ factorial designs. The population of this study were 244 students on the fourth grade of SDN Moh. Hatta in academic year of 2018/2019. The sample technique used in this study was purposive sample. The data were collected using test and non-test methods. The data analysed by 2-lane variance analysis. Based on the results of the analysis, it obtained that (1). It signifies that "there is a significant difference in Mathematical competency between group of students who are taught through cooperative learning model of Pair Checks type and group of students who are taught using conventional learning", (2). It means that "there is no significant difference in Mathematical competency between students who have high interpersonal intelligence and students who have low interpersonal intelligence", (3) It means that "there is no significant interaction between cooperative learning model of Pair Checks type and interpersonal intelligence on Mathematical competency. The results of the treatment effectiveness calculation obtained $\eta^{2}=0,052$. Overall, it can be concluded that the application of the learning model has an influence on the Mathematical competency by 5,2\%.

Copyright @ Universitas Pendidikan Ganesha. All rights reserved. 


\section{Pendahuluan}

Pendidikan adalah suatu wadah untuk mengembangkan kemampuan dan membentuk watak peserta didik dalam mencerdaskan kehidupan bangsa. Untuk itu, sangat diperlukan peningkatan dalam mutu pendidikan khususnya di Indonesia. Berbagai hal telah diupayakan oleh pemerintah untuk meningkatkan mutu pendidikan, salah satunya melalui peningkatan kualitas pembelajaran dan pembaharuan kurikulum. Sesuai dengan Permendikbud Nomor 57 Tahun 2014 tentang Kurikulum 2103 Sekolah Dasar/Madrasah Ibtidaiyah, struktur Kurikulum merupakan pengorganisasian Kompetensi Inti, Kompetensi Dasar, muatan pembelajaran, mata pelajaran, dan beban belajar. Kompetensi Inti pada Kurikulum 2013 Sekolah Dasar merupakan tingkat kemampuan untuk mencapai Standar Kompetensi Lulusan yang harus dimiliki seorang siswa SD pada setiap tingkat kelas. Dengan mengacu pada Kompetensi Inti, Kompetensi Dasar pada Kurikulum 2013 berisikan kemampuan dan muatan pembelajaran untuk suatu tema pembelajaran atau mata pelajaran di SD. Salah satu muatan pembelajaran yang terdapat pada Kurikulum 2013 di SD adalah pembelajaran Matematika.

Matematika memiliki peranan penting dalam berbagai aspek kehidupan. Banyak permasalahan dan kegiatan dalam kehidupan yang harus diselesaikan dengan ilmu matematika, seperti halnya mengukur, menimbang, menghitung, dan sebagainya (Ahmad, 2013). Begitu pentingnya peranan matematika, seharusnya membuat matematika menjadi salah satu mata pelajaran yang menyenangkan dan disukai oleh siswa, tetapi masih banyak siswa yang menganggap matematika sebagai salah satu mata pelajaran yang dianggap sulit, membosankan, dan tidak menarik. Di satu sisi matematika sangat berperan penting dalam kehidupan sehari-hari dalam meningkatkan daya nalar, berfikir logis, kreatif, kritis, dan memecahkan masalah dalam kehidupan sehari-hari, sedangkan di sisi lain ketidakmaksimalan siswa dalam memahami pelajaran matematika mengakibatkan siswa enggan, dan kurang minatnya siswa dalam mempelajari mata pelajaran matematika.

Berdasarkan data yang didapatkan setelah melakukan observasi pada hari Rabu, 5 November 2018 di UPT. Dinas Pendidikan Pemuda dan Olahraga Kec. Denpasar Selatan, nilai matematika pada saat ujian nasional tahun 2018 belum sesuai dengan yang diharapkan. Hal ini terbukti dengan diperolehnya data nilai matematika bahwa rata-rata nilai ujian matematika tahun 2018 adalah 65,66 dengan kriteria C. Hasil ini lebih rendah dari rata-rata mata pelajaran lain seperti IPA dan Bahasa Indonesia dengan nilai kategori B. Dari informasi yang diperoleh setelah melakukan observarsi pada hari Senin, 12 November 2018 pada guru kelas IV di SD Negeri Gugus Moh. Hatta dalam proses pembelajaran matematika masih banyak terdapat kendala-kendala yang mempengaruhi kompetensi pengetahuan matematika siswa. Kendala tersebut terjadi dalam proses pembelajaran yaitu, kurangnya interaksi antara siswa dengan siswa lain dan siswa dengan sumber belajarnya, sehingga siswa kurang berpartisipasi secara aktif. Dan pada mata pelajaran matematika masih banyak siswa yang mendapat nilai rendah diantara nilai mata pelajaran lain. Belum tercapainya kompetensi pengetahuan Matematika siswa dapat didasari oleh berbagai faktor yakni dapat dilihat dari faktor kecerdasan siswa dan faktor cara guru membuat siswa memahami materi dengan berbantuan model - model pembejaran. Guru saat ini sudah sebagaian besar mampu menerapkan beberapa model pembelajaran namun terkadang beberapa model itu tidak mampu membuat siswa mudah memahami setiap materi pembelajaran. Kekurangan ini mampu berdampak pada penurunan kompetensi pengetahuan Matematika yang dimilki siswa. Oleh karena itu, perlunya guru harus mampu proaktif memilih model - model pembelajaran yang mampu memacu semangat siswa dalam belajar, sehingga berdampak pada kompetensi pengetahuan Matematika siswa. Pembelajaran inovatif adalah pembelajaran yang lebih bersifat student centered. Artinya, pembelajaran yang lebih memberikan peluang kepada siswa untuk mengkonstruksi pengetahuan secara mandiri (self directed) dan dimediasi oleh teman sebaya (peer mediated instruction) ((Aris, 2014). Cooperative Learning berasal dari dua kata yaitu Cooperative dan Learning. Cooperative berarti kerjasama dan Learning berarti belajar. Jadi, Cooperative Learning merupakan belajar melalui kegiatan bersama (Huda, 2014). Salah satu model yang dapat diterapkan adalah model pembelajaran kooperatif. (Isjoni, 2014) “Cooperative learning adalah suatu model pembelajaran dimana sistem belajar dan bekerja dalam kelompok-kelompok kecil yang berjumlah 4-6 orang secara kolaboratif sehingga dapat merangsang siswa lebih bergairah dalam belajar". Pembelajaran kooperatif memiliki berbagai tipe, salah satunya adalah koopertif tipe pair checks. Menurut Herdian (Aris, 2014) model pair checks (pasangan mengecek) merupakan "model pembelajaran dimana siswa saling berpasangan dan menyelesaikan persoalan yang diberikan. Dalam model pembelajaran kooperatif tipe pair checks, guru bertindak sebagai motivator dan fasilitator aktivitas siswa". Model pembelajaran ini juga untuk melatih rasa sosial siswa, kerja sama, dan kemampuan memberi penilaian. Model ini bertujuan untuk meningkatkan kemampuan siswa dalam menuangkan ide, pikiran, dan pendapatnya. Dengan ini, siswa untuk saling bertukar pendapat dan saran. 
Agar model pembelajaran kooperatif ini berjalan sesuai dengan yang diharapkan, maka harus ada faktor yang mendukung, salah satunya adanya interaksi individu dalam kelompok. Interaksi itu disebut dengan kecerdasan interpersonal. Kecerdasan interpersonal adalah kecerdasan yang menunjukkan kemampuan seseorang untuk peka terhadap perasaan orang lain, mereka cenderung untuk memahami dan berinteraksi dengan orang lain sehingga mudah bersosialisasi dengan lingkungan di sekelilingnya. Kecerdasan interpersonal berkaitan dengan kemampuan siswa dalam menjalin kerjasama yang baik dan bertujuan untuk mengembangkan keterampilan sosial (social skill). Melalui program pendidikan yang dirancang dengan baik, anak akan mampu mengembangkan segenap potensi yang dimiliki, dari aspek fisik, sosial, moral, emosi, kepribadian dan lain-lain (Safaria, 2005). Melalui penerapan model ini dan adanya faktor pendukung yaitu kecerdasan interpersonal yang dimiliki oleh siswa, siswa yang mengalami kesulitan belajar mampu saling berinteraksi dalam memberikan masukan/saran, membimbing temannya sehingga memudahkan dalam menyelesaikan masalah dalam kelompok.

\section{Metode}

Penelitian ini dilaksanakan pada semester 2 tahun ajaran 2018/2019. Penelitian ini merupakan eksperimen semu dengan rancangan factorial Design $2 \times 2$. Populasi penelitian ini adalah siswa kelas IV SDN Gugus Moh. Hatta tahun ajaran 2018/2019, dengan jumlah siswa 244 orang. Dalam penentuan sampel penelitian digunakan teknik purposif sampling. Berdasarkan pertimbangan tertentu dan kebijakan sekolah, maka penelitian hanya dapat dilakukan pada 4 kelas dari 3 sekolah. Jadi, kelas yang akan dijadikan sampel penelitian adalah kelas dari sekolah yang memberikan akses untuk melakukan penelitian. Untuk memilih kelompok kontrol dan kelompok eksperimen dilakukan secara acak. SDN yang terpilih sebagai kelompok kontrol adalah kelas IV SDN 4 Panjer yang berjumlah 43 orang dan SDN yang terpilih sebagai kelompok eksperimen adalah kelas IV SDN 2 Panjer yang berjumlah 39 orang. Data dikumpulkan menggunakan metode tes yaitu soal pilihan ganda biasa dan non-tes yaitu kuesioner. Pada kelompok eksperimen dan kelompok kontrol diberikan kuesioner kecerdasan interpersonal dan pretest, dilanjutkan dengan perlakuan sebanyak 6 kali pertemuan, kemudian diberikan posttest. Data hasil kuesioner dianalisis untuk mengetahui skor kecerdasan interpersonal yang kemudian dikategorikan sebagai kelompok siswa dengan kecerdasan interpersonal tinggi dan rendah menggunakan batas median. Sebelum proses pengkategorian kecerdasan interpersonal 3 sampel dengan rentangan skor terlalu rendah tidak dianalisis agar kecerdasan interpersonal tinggi pada kelompok kontrol dan kelompok eksperimen setara, kecerdasan interpersonal rendah pada kelompok kontrol dan kelompok eksperimen setara, serta kecerdasan interpersonal tinggi maupun rendah pada masing-masing kelompok berbeda. Sedangkan pada kelompok eksperimen 1 orang siswa dengan skor kecerdasan interpersonal pada batas median dihilangkan. Uji hipotesis dilakukan dengan cara menganalisis data gain score yang diperoleh dari hasil pretest dan posttest menggunakan analisis variansi 2 jalur. Sebelum melakukan uji hipotesis, dilakukan analisis prasyarat yang harus dipenuhi yaitu uji normaitas dan uji homogenitas. Setelah dilakukan uji hipotesis, untuk mengetahui berapa besar pengaruh variabel bebas terhadap variabel terikat pada sampel dihitung menggunakan eta square.

\section{Hasil dan Pembahasan}

Data skor hasil kecerdasan interpesonal kelompok kontrol disajikan pada Gambar 1 berikut:

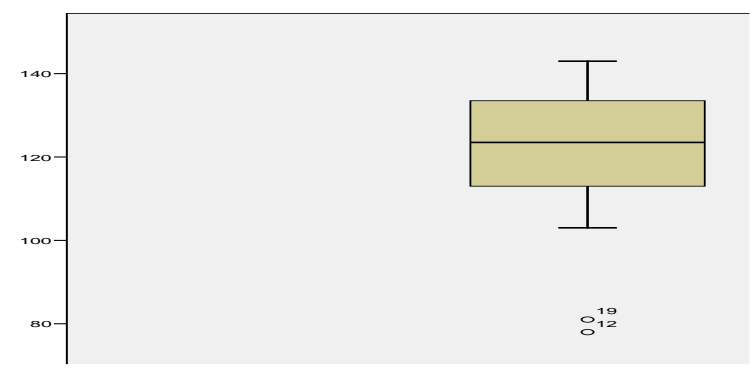

Gambar 1.

Grafik Box Plot Kecerdasan Interpersonal Kelompok Kontrol

Berdasarkan grafik box plot pada gambar 01 diketahui batas median kecerdasan interpersonal siswa kelompok kontrol adalah 123,5. Sehingga, siswa yang dikategorikan sebagai kelompok dengan 
kecerdasan interpersonal tinggi adalah siswa dengan skor kecerdasan interpersonal yang lebih dari 123,5. Sedangkan, siswa yang dikategorikan sebagai kelompok dengan kecerdasan interpersonal rendah adalah siswa dengan skor kecerdasan interpersonal yang kurang dari 123,5. Nilai maksimum kecerdasan interpersonal siswa kelompok kontrol adalah 143 dan nilai minimum adalah 78. Berikut adalah distribusi data kecerdasan interpersonal yang disajikan pada Gambar 2.

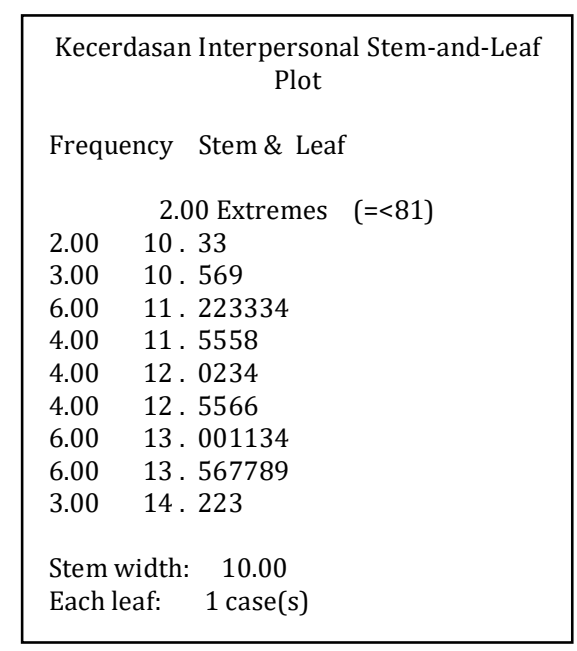

Gambar 2.

Grafik Steam and Leaf Kecerdasan Interpersonal Kelompok Kontrol

Data skor hasil kecerdasan interpersonal kelompok eksperimen disajikan pada Gambar 3 berikut.

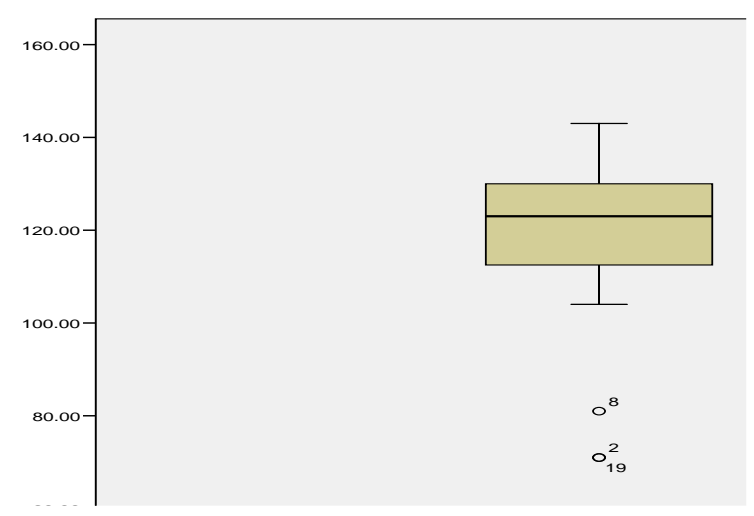

\section{Gambar 3.}

Grafik Box Plot Kecerdasan Interpersonal Kelompok Eksperimen

Berdasarkan Gambar 3, diketahui bahwa batas median kecerdasan interpersonal siswa kelompok eksperimen adalah 123. Sehingga, siswa yang dikategorikan sebagai kelompok dengan kecerdasan interpersonal tinggi adalah siswa dengan skor kecerdasan interpersonal yang lebih dari 123. Sedangkan, siswa yang dikategorikan sebagai kelompok dengan kecerdasan interpersonal rendah adalah siswa dengan skor kecerdasan interpersonal yang kurang dari 123. Nilai maksimum kecerdasan interpersonal siswa kelompok eksperimen adalah 143 dan nilai minimum adalah 71. Berikut adalah distribusi data kecerdasan interpersonal yang disajikan pada Gamabar 4. 


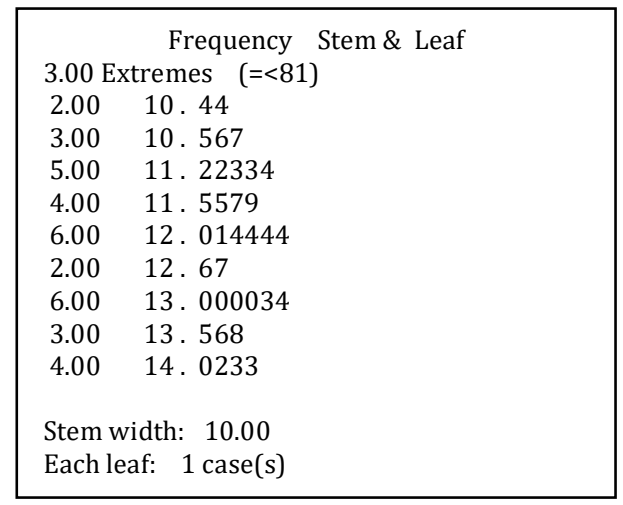

Gambar 4.

Grafik Steam and Leaf Kecerdasan Interpersonal Kelompok Eksperimen

Untuk mengetahui kesetaraan kecerdasan interpersonal siswa kelompok kontrol dan kelompok eksperimen diuji menggunakan uji t-test independen dua sampel. Adapun hasil uji t-test independen dua sampel disajikan pada Tabel 1 berikut.

Tabel 1. Hasil Uji T-Test Independen Dua Sampel

\begin{tabular}{|c|c|c|c|c|c|}
\hline No & Kategori & $\mathbf{t}_{\text {hitung }}$ & $t_{\text {tabel }}$ & Keputusan & Keterangan \\
\hline 1. & $\begin{array}{l}\text { Kecerdasan interpersonal } \\
\text { tinggi pada kelompok kontrol } \\
\text { dan kecerdasan interpersonal } \\
\text { tinggi pada kelompok } \\
\text { eksperimen }\end{array}$ & 0,445 & 2,026 & $\mathrm{H}_{0}$ Diterima & $\begin{array}{l}\text { Tidak terdapat perbedaan } \\
\text { kecerdasan interpersonal } \\
\text { tinggi pada kelompok } \\
\text { kontrol dan kecerdasan } \\
\text { interpersonal tinggi pada } \\
\text { kelompok eksperimen }\end{array}$ \\
\hline 2. & $\begin{array}{l}\text { Kecerdasan interpersonal } \\
\text { rendah pada kelompok } \\
\text { kontrol dan kecerdasan } \\
\text { interpersonal rendah pada } \\
\text { kelompok eksperimen }\end{array}$ & 0,709 & 2,026 & $\mathrm{H}_{0}$ Diterima & $\begin{array}{l}\text { Tidak terdapat perbedaan } \\
\text { kecerdasan interpersonal } \\
\text { rendah pada kelompok } \\
\text { kontrol dan kecerdasan } \\
\text { interpersonal rendah pada } \\
\text { kelompok eksperimen }\end{array}$ \\
\hline 3. & $\begin{array}{l}\text { Kecerdasan interpersonal } \\
\text { tinggi dan kecerdasan } \\
\text { interpersonal rendah pada } \\
\text { kelompok kontrol }\end{array}$ & 7,834 & 2,024 & $\mathrm{H}_{0}$ Ditolak & $\begin{array}{l}\text { Terdapat perbedaan } \\
\text { Kecerdasan interpersonal } \\
\text { tinggi dan kecerdasan } \\
\text { interpersonal rendah pada } \\
\text { kelompok kontrol }\end{array}$ \\
\hline 4. & $\begin{array}{l}\text { Kecerdasan interpersonal } \\
\text { tinggi dan kecerdasan } \\
\text { interpersonal rendah pada } \\
\text { kelompok eksperimen }\end{array}$ & 6,609 & 2,028 & $\mathrm{H}_{0}$ Ditolak & $\begin{array}{l}\text { Terdapat perbedaan } \\
\text { Kecerdasan interpersonal } \\
\text { tinggi dan kecerdasan } \\
\text { interpersonal rendah pada } \\
\text { kelompok eksperimen }\end{array}$ \\
\hline
\end{tabular}

Berdasarkan Tabel 1, dapat disimpulkan bahwa kecerdasan interpersonal tinggi dan rendah pada kelompok kontrol tidak terdapat perbedaan dengan kecerdasan interpersonal tinggi dan rendah pada kelompok eksperimen. Terdapat perbedaan kecerdasan interpersonal tinggi dan kecerdasan interpersonal rendah pada kelompok kontrol. Terdapat perbedaan kecerdasan interpersonal tinggi dan kecerdasan interpersonal rendah pada kelompok eksperimen. Selanjutnya dianalisis data pretest dan posttest untuk mendapatkan nilai Gain Score.

Berdasarkan tes kompetensi pengetahuan matematika untuk materi statistika diperoleh data pretest kelompok kontrol disajikan dalam grafik steam and leaf seperti pada Gambar 5. 


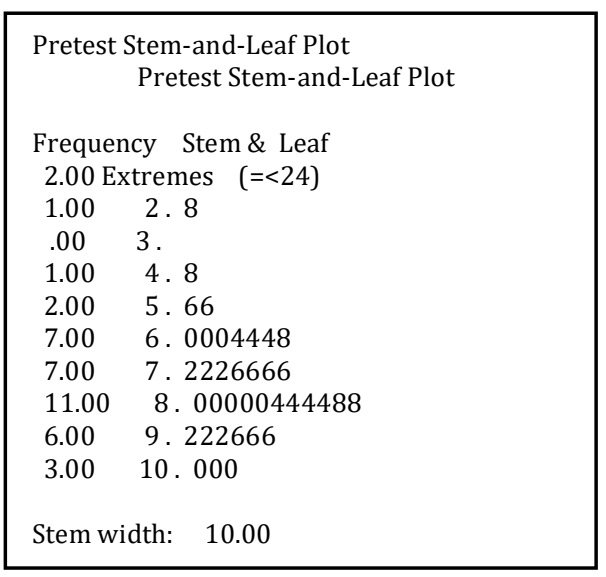

\section{Gambar 5.}

Grafik Steam and Leaf Data Pretest Kelompok Kontrol

Berdasarkan Gambar 5, diketahui data hasil pretest kelompok kontrol dengan jumlah data extremes yaitu $\leq 24$ sebanyak 2 data. Nilai minimum yaitu 24 sebanyak 2 data, nilai maksimum yaitu 100 sebanyak 3 data dan rentangan nilai terbanyak yaitu 80-88 sebanyak 11 data. Dalam sub bab 4.1.3.2 akan dibahas mengenai data hasil posttest kelompok kontrol.

Berdasarkan tes kompetensi pengetahuan matematika untuk materi statistika diperoleh data posttest kelompok kontrol disajikan dalam grafik steam and leaf seperti pada Gambar 6.

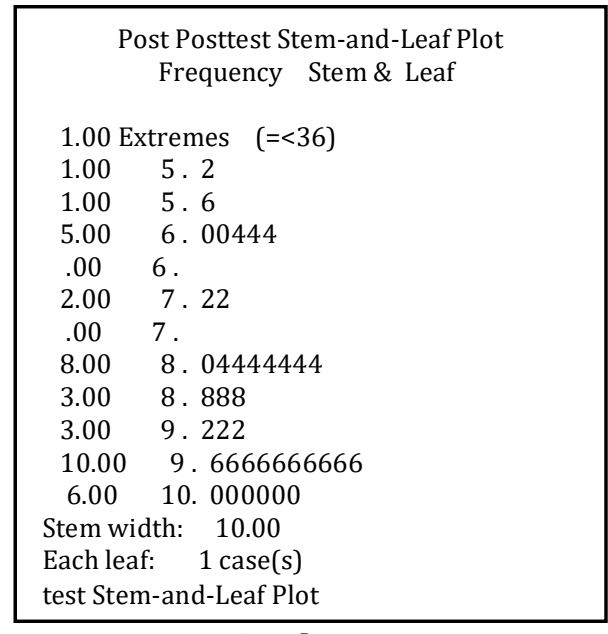

\section{Gambar 6.}

Grafik Steam and Leaf Data Posttest Kelompok Kontrol

Berdasarkan Gambar 6, diketahui data hasil posttest siswa yang dibelajarkan dengan model pembelajaran konvensional dengan jumlah data extremes yaitu $\leq 36$ sebanyak 1 data. Nilai minimum yaitu 36 sebanyak 1 data, nilai maksimum yaitu 100 sebanyak 6 data dan nilai terbanyak yaitu 96 sebanyak 10 data.

Berdasarkan tes kompetensi pengetahuan matematika untuk materi statistika diperoleh data pretest kelompok eksperimen disajikan dalam grafik steam and leaf seperti pada Gambar 7. 


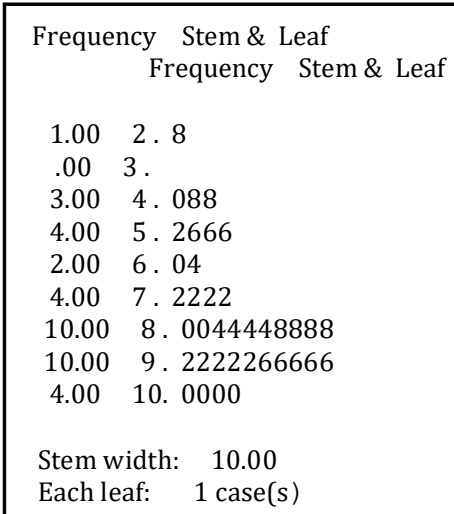

\section{Gambar 7.}

Grafik Steam and Leaf Data Pretest Kelompok Eksperimen

Berdasarkan Gambar 7, diketahui nilai minimum yaitu 28 sebanyak 1 data, nilai maksimum yaitu 100 sebanyak 4 data dan rentangan nilai terbanyak yaitu 80-88 sebanyak 10 data dan 92-96 sebanyak 10 data. Dalam sub bab 4.1.4.2 akan dibahas mengenai data hasil posttest kelompok eksperimen.

Berdasarkan tes kompetensi pengetahuan matematika materi statistika diperoleh data posttest kelompok eksperimen disajikan dalam grafik steam and leaf seperti pada Gambar 8.

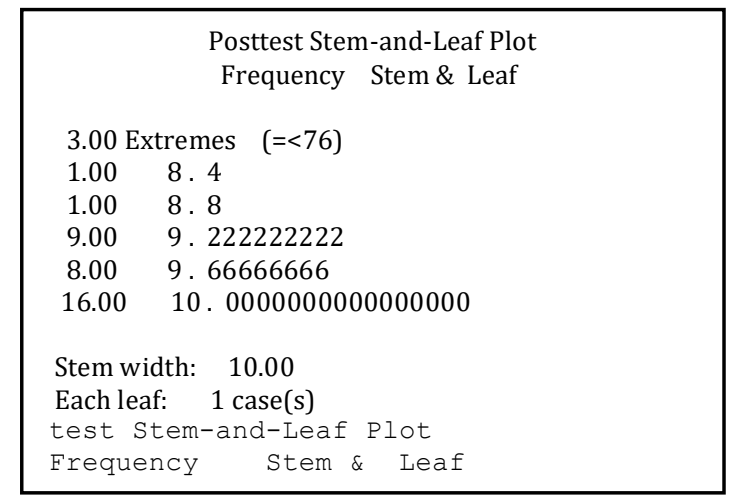

\section{Gambar 8.}

Grafik Steam and Leaf Data Posttest Kelompok Eksperimen

Berdasarkan Gambar 8, diketahui data hasil posttest kelompok eksperimen dengan jumlah data extremes yaitu $\leq 76$ sebanyak 3 data. Nilai minimum yaitu 84 sebanyak 1 data, nilai maksimum yaitu 100 sebanyak 16 data dan nilai terbanyak yaitu 100 sebanyak 16 data.

Hasil uji normalitas sebaran data gain score disajikan pada Tabel 2 berikut.

Tabel 2. Hasil Normalitas Sebaran Data Gain Score

\begin{tabular}{lllll}
\hline \multicolumn{1}{c}{ Kelompok } & \multicolumn{1}{c}{$\begin{array}{c}\text { Nilai } \\
\text { Maksimum } \\
\left|\mathrm{F}_{\mathrm{T}}-\mathbf{F}_{\mathrm{S}}\right|\end{array}$} & $\begin{array}{c}\text { Nilai Tabel } \\
\text { Kolmogorov- } \\
\text { Smirnov }\end{array}$ & Keterangan \\
\hline $\begin{array}{l}\text { Kelompok kontrol siswa dengan kecerdasan } \\
\text { interpersonal tinggi }\end{array}$ & 0,256 & 0,304 & $\begin{array}{l}\text { Berdistribusi } \\
\text { normal }\end{array}$ \\
$\begin{array}{l}\text { Kelompok kontrol siswa dengan kecerdasan } \\
\text { interpersonal rendah }\end{array}$ & 0,236 & 0,304 & $\begin{array}{l}\text { Berdistribusi } \\
\text { normal }\end{array}$ \\
$\begin{array}{l}\text { Kelompok eksperimen siswa } \\
\text { kecerdasan interpersonal tinggi }\end{array}$ & dengan & 0,243 & 0,312 & $\begin{array}{l}\text { Berdistribusi } \\
\text { normal } \\
\text { Kelompok eksperimen siswa } \\
\text { kecerdasan interpersonal rendah }\end{array}$ \\
\hline
\end{tabular}

Kriteria pengujian adalah apabila nilai maksimum $\left|F_{T}-F_{S}\right| \leq$ nilai tabel Kolmogorov-Smirnov, maka data berdistribusi normal. Sebaliknya jika nilai maksimum $\left|\mathrm{F}_{\mathrm{T}}-\mathrm{F}_{\mathrm{S}}\right|>$ nilai tabel Kolmogorov- 
Smirnov, maka data tidak berdistribusi normal. Berdasarkan tabel 03, dapat disimpulkan data berdistribusi normal.

Untuk menguji homogenitas variansi keempat kelompok digunakan uji Bartlett disajikan pada Tabel 3 berikut.

Tabel 3. Uji Homogenitas Variansi Keempat Kelompok

\begin{tabular}{ccc}
\hline Nilai $\chi^{2}$ hitung & Nilai $\chi^{2}$ tabel & Keterangan \\
\hline 1,860 & 7,815 & Homogen \\
\hline
\end{tabular}

Dari hasil perhitungan diperoleh nilai $\chi^{2}$ hitung $=1,860$. Sedangkan nilai $\chi^{2}$ tabel $=7,815$. Dengan taraf signifikansi 5\% $(\alpha=0,05)$ dengan derajat kebebasan 4-1=3. Maka nilai $\chi^{2}$ hitung $=1,860<$ nilai $\chi^{2}$ tabel $=$ 7,815 yang disimpulkan bahwa data keempat kelompok memiliki variansi yang homogen.

Data yang telah diuji normalitas dan homogenitasnya selanjutnya dilakukan uji hipotesis dengan analisis variansi dua jalur. Berikut rekapitulasi hasil analisis variansi 2 jalur kelompok sampel penelitian ini disajikan dalam Tabel 4.

Tabel 4. Rekapitulasi Hasil ANAVA 2 Jalur Kelompok Sampel Penelitian

\begin{tabular}{llllllc}
\hline \multicolumn{1}{c}{ Sumber Variasi } & db & \multicolumn{1}{c}{ JK } & \multicolumn{1}{c}{ MK } & \multicolumn{1}{c}{ F $_{\text {hitung }}$} & \multicolumn{1}{c}{$\mathbf{F}_{\text {tabel }}$ (5\%) } & Keputusan \\
\hline Antar A & 1 & 725,118 & 725,118 & 4,059 & 3,970 & $\mathrm{H}_{0}$ ditolak \\
Antar B & 1 & 34,667 & 34,667 & 0,194 & 3,970 & $\mathrm{H}_{0}$ diterima \\
Interaksi A x B & 1 & 87,670 & 87,670 & 0,491 & 3,970 & $\mathrm{H}_{0}$ diterima \\
Dalam & 4 & 13221,263 & 178,666 & - & - & - \\
Total & 7 & 14068,718 & - & - & - & - \\
\hline
\end{tabular}

Berdasarkan hasil analisis yang tercantum dalam tabel 4 ringkasan analisis variansi dua jalur tersebut, dapat disimpulankan yaitu 1) $\mathrm{F}_{\mathrm{A}}=4,059>3,970$, sehingga hipotesis nol $\left(\mathrm{H}_{\mathrm{o}}\right)$ yang menyatakan tidak terdapat perbedaan yang signifikan kompetensi pengetahuan Matematika antara kelompok siswa yang dibelajarkan melalui model pembelajaran kooperatif tipe pair checks dan kelompok siswa yang dibelajarkan menggunakan pembelajaran konvensional ditolak. 2) $F_{B}=0,194<3,970$, sehingga hipotesis nol $\left(\mathrm{H}_{\mathrm{o}}\right)$ yang menyatakan terdapat perbedaan yang signifikan kompetensi pengetahuan Matematika antara siswa yang memiliki kecerdasan interpersonal tinggi dan siswa yang memiliki kecerdasan interpersonal rendah pada kompetensi pengetahuan Matematika diterima. Hal ini dikarenakan siswa mampu memecahkan masalah dalam pembelajaran Matematika hanya dengan memahami permasalahan yang diberikan tanpa perlu menjelaskan permasalahan tersebut secara lisan. Dampak dari hal tersebut, baik siswa yang memiliki kecerdasan interpersonal tinggi maupun rendah hanya perlu memahami pembelajaran matematika, 3) $\mathrm{F}_{\mathrm{AB}}=0,491<3,970$, sehingga hipotesis nol $\left(\mathrm{H}_{0}\right)$ yang menyatakan tidak terdapat interaksi yang signifikan model pembelajaran kooperatif tipe pair checks dan kecerdasan interpersonal terhadap kompetensi pengetahuan Matematika diterima. Hal ini dilihat karena siswa yang dibelajarakan dengan model kooperatif tipe pair checks lebih tinggi dibandingkan dengan siswa yang dibelajarakan mengggunakan pembelajaran konvensional, baik pada kecerdaan interpersonal tinggi maupun rendah. Selain hal tersebut, siswa mampu memecahkan masalah dalam pembelajaran Matematika hanya dengan memahami permasalahan yang diberikan tanpa perlu menjelaskan permasalahan tersebut secara lisan. Dampak dari hal tersebut, baik siswa yang memiliki kecerdasan interpersonal tinggi maupun rendah hanya perlu memahami pembelajaran matematika. Berdasarkan data kecerdasan interpersonal, siswa hanya cukup dibelajarkan dengan model pembelajaran kooperatif, sehingga interaksi antara model pembelajaran dan kecerdasan interpersonal tidak terjadi.

Tidak terdapat interaksi yang signifikan antara model pembelajaran kooperatif tipe pair checks dan kecerdasan interpersonal terhadap kompetensi pengetahuan Matematika tersebut divisualisasikan melalui grafik pada Gambar 9 berikut. 

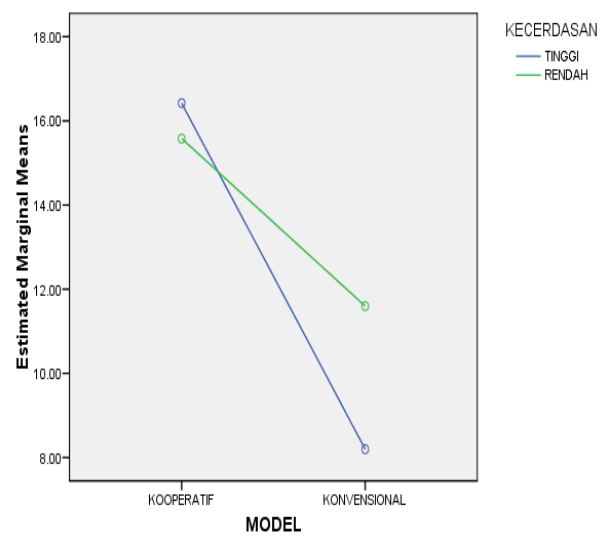

Gambar 9.

Grafik Interaksi Model Pembelajaran Dan Kecerdasan Interpersonal

Berdasarkan Gambar 9, diketahui model pembelajaran dan kecerdasan interpersonal tidak memiliki interaksi yang signifikan maka tidak dilanjutkan dengan uji lanjut sel.

Berdasarkan pengujian hipotesis pertama, diperoleh hasil bahwa terdapat pengaruh yang signifikan model pembelajaran kooperatif tipe pair checks terhadap kompetensi pengetahuan Matematika. Besarnya pengaruh model terhadap kompetensi pengetahuan Matematika dapat ditentukan dengan melakukan perhitungan efektivitas. Dari hasil perhitungan eta squre, diperoleh nilai $\eta^{2}=0,052$. Sehingga dapat disimpulkan bahwa penerapan model pembelajaran memiliki pengaruh terhadap kompetensi pengetahuan Matematika sebesar 5,2\%.

\section{Simpulan dan Saran}

Sesuai dengan hasil penelitian dan pembahasan, maka dapat disimpulkan 1) berdasarkan $\mathrm{F}_{\text {hitung }}$ dari sumber variansi antar A diperoleh $F_{A}=4,059>F$ tabel $\left.(\alpha=0,05 ; 1 ; 74)\right)=3,970$, sehingga hipotesis nol $\left(H_{0}\right)$ yang menyatakan tidak terdapat perbedaan yang signifikan kompetensi pengetahuan Matematika antara kelompok siswa yang dibelajarkan melalui model pembelajaran kooperatif tipe pair checks dan kelompok siswa yang dibelajarkan menggunakan pembelajaran konvensional ditolak. Hal ini berarti terdapat perbedaan yang signifikan kompetensi pengetahuan Matematika antara kelompok siswa yang dibelajarkan melalui model pembelajaran kooperatif tipe pair checks dan kelompok siswa yang dibelajarkan menggunakan pembelajaran konvensional. Dilihat dari rata-rata gain score, tampak bahwa kompetensi pengetahuan Matematika kelompok siswa yang dibelajarkan menggunakan model pembelajaran kooperatif tipe pair checks $\bar{X} \mathrm{~A}_{1}=16,0>\bar{X} \mathrm{~A}_{2}=9,9$ kelompok siswa yang dibelajarkan tidak menggunakan pembelajaran konvensional. Dengan kata lain, model pembelajaran kooperatif tipe pair checks berpengaruh terhadap kompetensi pengetahuan Matematika siswa kelas IV SDN Gugus Moh.Hatta, 2) berdasarkan $F_{\text {hitung }}$ dari sumber variansi antar B diperoleh $F_{B}=0,194<F$ tabel $\left.(\alpha=0,05 ; 1 ; 74)\right)=$ 3,970 . Sehingga hipotesis nol $\left(\mathrm{H}_{0}\right)$ yang menyatakan tidak terdapat perbedaan yang signifikan kompetensi pengetahuan Matematika antara siswa yang memiliki kecerdasan interpersonal tinggi dan siswa yang memiliki kecerdasan interpersonal rendah pada kompetensi pengetahuan Matematika diterima. Hal ini berarti secara keseluruhan tidak terdapat perbedaan yang signifikan kompetensi pengetahuan Matematika antara siswa yang memiliki kecerdasan interpersonal tinggi dan siswa yang memiliki kecerdasan interpersonal rendah pada kompetensi pengetahuan Matematika. Dengan demikian kecerdasan interpersonal tidak memiliki pengaruh terhadap kompetensi pengetahuan Matematika, 3)

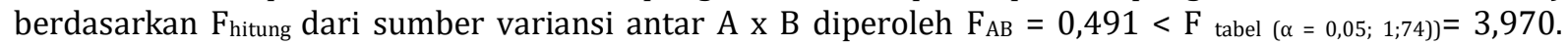
Sehingga hipotesis nol $\left(\mathrm{H}_{0}\right)$ yang menyatakan tidak terdapat interaksi yang signifikan model pembelajaran kooperatif tipe pair checks ditinjau dari kecerdasan interpersonal terhadap kompetensi pengetahuan Matematika diterima. Hal ini berarti secara keseluruhan tidak terdapat interaksi model pembelajaran kooperatif tipe pair checks dan kecerdasan interpersonal terhadap kompetensi pengetahuan Matematika kelas IV SD Negeri Gugus Moh. Hatta tahun ajaran 2018/2019, (4) berdasarkan hasil perhitungan eta squre $\left(\eta^{2}\right)$, diperoleh nilai kriteria $\eta^{2}=0,052$ Sehingga penerapan model pembelajaran memiliki pengaruh terhadap kompetensi pengetahuan Matematika sebesar 5,2\%. 
Berdasarkan hasil penelitian yang telah disimpulkan, terdapat beberapa saran yang disampaikan kepada berbagai pihak yaitu 1) guru hendaknya dapat menambah wawasannya mengenai inovasi pembelajaran sehingga mampu menerapkan dan mengembangkan pembelajaran di kelas secara lebih inovatif dan bervariasi agar dapat memberikan dampak positif dalam peningkatan kompetensi pengetahuan siswa. Salah satu model pembelajaran yang dapat direkomdasikan untuk guru dalam menciptakan pembelajaran yang bervariasi adalah model pembelajaran kooperatif tipe pair checks. Guru juga harus meningkatkan perannya sebagai motivator dan fasilitator, 2) kepala sekolah hendaknya dapat berkontribusi penuh dalam meningkatkan kualitas serta mengoptimalkan proses pembelajaran, sehingga berdampak positif pada kompetensi pengetahuan siswa khususnya di sekolah dasar, 3) berdasarkan temuan penelitian, disarankan kepada peneliti agar hasil penelitian ini digunakan sebagai referensi untuk melaksanakan penelitian selanjutnya atau menemukan inovasi kegiatan pembelajaran lainnya yang bermakna bagi siswa.

\section{Daftar Rujukan}

Ahmad, S. (2013). Teori Belajar dan Pembelajaran di Sekolah Dasar. Kencana Prenada Media Group.

Aris, S. (2014). Model pembelajaran Inovatif Dalam Kurikulum 2013. In 1 (Issue). Yogyakarta: AR-ruz media.

Huda, M. (2014). Cooperative Learning. Pustaka Pelajar.

Isjoni. (2014). Cooperative Learning Mengembangkan Kemampuan Belajar Berkelompok. Alfabeta.

Safaria. (2005). Interpersonal Intelligence. Ambara Books. 